\title{
Enhancement of Mechanical and Thermal Properties of Poly(L-lactide) Nanocomposites Filled with Synthetic Layered Compounds
}

\author{
Telma Nogueira Caio, ${ }^{1}$ Núria Gonçalves, ${ }^{1}$ \\ Fernando Wypych, ${ }^{2}$ and Liliane Maria Ferrareso Lona ${ }^{1}$ \\ ${ }^{1}$ School of Chemical Engineering, University of Campinas, 13083-852 Campinas, SP, Brazil \\ ${ }^{2}$ Chemistry Department, Federal University of Paraná, 81531-980 Curitiba, PR, Brazil \\ Correspondence should be addressed to Telma Nogueira Caio; telma.nogueira@gmail.com
}

Received 7 March 2017; Revised 21 June 2017; Accepted 13 August 2017; Published 17 September 2017

Academic Editor: Eliane Espuche

Copyright ( $) 2017$ Telma Nogueira Caio et al. This is an open access article distributed under the Creative Commons Attribution License, which permits unrestricted use, distribution, and reproduction in any medium, provided the original work is properly cited.

\begin{abstract}
The effects of a layered double hydroxide (LDH) ( $\mathrm{Zn} / \mathrm{Al}$ palmitate) and two layered hydroxide salts (LHS), intercalated with the anion salicylate or palmitate, on the properties of poly(L-lactide) (PLLA) nanocomposites were investigated. PLLA and the nanocomposites were synthesized by ring opening polymerization of the cyclic dimer of lactic acid (lactide), using tin(II) 2ethylhexanoate (stannous octanoate) as catalyst. PLLA nanocomposites containing two different fillers concentrations ( $1 \mathrm{wt} \%$ and $2 \mathrm{wt} \%)$ were produced. Compared to PLLA, almost all the nanocomposites exhibited an enhancement on thermal resistance. The sample containing $1 \mathrm{wt} \%$ of $\mathrm{Zn} / \mathrm{Al}$ palmitate exhibited a decomposition temperature $51^{\circ} \mathrm{C}$ higher than neat polymer. Results of flexural properties demonstrated that the nanocomposites containing $\mathrm{Zn} / \mathrm{Al}$ palmitate displayed the highest values of maximum flexural stress and elongation at break. The sample with $2 \mathrm{wt} \%$ of this filler revealed values of maximum flexural stress and strain at break, $15 \%$ and $157 \%$, respectively, higher than PLLA. Contrary to PLLA, which only exhibited break point, this nanocomposite showed a less fragile behavior, as a yield point was observed. In this case, it was possible to promote a higher flexibility without reducing the flexural stress, revealing an advantage of the $\mathrm{Zn} / \mathrm{Al}$ palmitate under the plasticizers that have been used so far for PLLA.
\end{abstract}

\section{Introduction}

Recently, biodegradable polymers have attracted a large amount of attention, because there is a global concern on the reduction of the environmental impact generated by nondegradable polymers. For this reason, there is an urgent need to develop renewable source-based environmental benign plastic materials, especially in short-term packaging and disposable applications that would not involve the use of toxic or noxious components in their manufacture and could allow the composting of naturally occurring degradation products [1]. Among these ecological materials, poly(L-lactide) (PLLA) has drawn intensive attention for their outstanding biocompatibility and biodegradability as well as physical properties which are comparable with polystyrene (PS) and polyethylene terephthalate (PET) [2]. However, the largescale use of PLLA as packaging material is still hampered by its high cost and low performance compared to commodity polymers [3]. In order to try to enhance mechanical, thermal, and gas barrier properties of PLLA, some scientific groups have already studied the incorporation of some nanoscale layered synthetic inorganic reinforcements like layered double hydroxides (LDHs) on this polymeric matrix [2, 4-10]. Although the effect of LDHs on the mechanical and/or thermal properties of PLLA nanocomposites has already been investigated, studies considering PLLA nanocomposites filled with LDH-palmitate were not found. This anion was selected because preview promising results [11] demonstrated that it was possible to enhance PMMA properties by the addition of low concentrations of LDHs intercalated by long-chain 
organic anions. The LDHs exhibit structures that derive from brucite. Brucite structure is based on infinite layers composed of octahedra that are connected to each other through their edges. Magnesium cations and hydroxyl groups occupy the center and vertices of the octahedra, respectively.

Brucite-like structures can experience other modifications, by either isomorphic substitution of cations in the layers or substitution of part of the hydroxide groups by appropriate anions or water molecules. In the latter case, additional anions must be present in the second coordination sphere in order to balance the charge of the layers [12]. These modifications generate the layered hydroxide salts (LHS), whose composition can be represented by the general formula: $M^{2+}(\mathrm{OH})_{2-x}\left(A^{m-}\right)_{x / m} n \mathrm{H}_{2} \mathrm{O}$, where $M^{2+}$ is the metallic cation and $A^{m-}$ is the intercalated hydrated counterion.

As far as the authors know, there are no studies on the production of poly(L-lactide) nanocomposites reinforced by layered hydroxide salts.

Katiyar and Nanavati [13] investigated the effect of montmorillonite clay, modified with surfactant, on the thermal stability and molecular weight of poly(L-lactic acid) nanocomposites. Compared to pure PLLA, all the nanocomposites exhibited higher temperatures of the onset degradation. The highest average molecular weight $(169000 \mathrm{Da})$ was observed for the nanocomposite containing $1 \mathrm{wt} \%$ of montmorillonite modified with dioctadecyl dimethyl ammonium bromide. For all the nanocomposites, as the clay concentration increased the molecular weight decreased.

Some authors [7] evaluated the mechanical properties of poly(lactic acid) nanocomposites containing $\mathrm{LDH}$-stearate in their compositions. Results demonstrated that the nanocomposite containing $1 \mathrm{wt} \%$ of $\mathrm{Mg} / \mathrm{Al} \mathrm{3:1}$ stearate exhibited a tensile strength value very similar to the one obtained for the neat polymer. However, as the filler concentration increased there was a decrease on this property. On the other hand, compared to neat polymer, the nanocomposites containing 1 and $3 \mathrm{wt} \%$ of filler revealed elongation at break values about seven times higher. Another research group [6] investigated the effects of the incorporation of two different fillers, LDH-laurate and organomodified montmorillonite clay, into poly(L-lactic acid) properties. Thermogravimetric analysis results showed that the nanocomposites containing LDH-laurate were much less thermally stable than PLLA or the nanocomposites containing modified montmorillonite. Compared to PLLA, oxygen and water vapor permeability were significantly reduced for the nanocomposites containing organomodified montmorillonite, but the addition of LDHlaurate did not cause an enhancement on the barrier properties.

In the present study, the effect of three different fillers, one LDH ( $\mathrm{Zn} / \mathrm{Al}$ (palmitate)) and two LHS (LHS (salicylate) and LHS (palmitate)), on the mechanical and thermal properties of poly(L-lactide) nanocomposites was investigated. The nanocomposites were synthesized by intercalative in situ bulk polymerization. Two different weight fractions of filler were evaluated ( 1 and $2 \mathrm{wt} \%$ ), in relation to the polymer mass. These concentrations were selected because previous studies of our group [14] demonstrated that higher loadings of layered compounds can adversely affect the mechanical properties of the polymer nanocomposites.

\section{Experimental}

2.1. Materials and Methods. (3S)-cis-3,6-Dimethyl-1,4-dioxane-2,5-dione (lactide) (98\%) (Purac), tin(II) 2-ethylhexanoate (stannous octoate) (95\%) (Sigma Aldrich), sodium hydroxide, ethanol, zinc chloride, zinc nitrate, ammonium hydroxide, salicylic acid (Ecibra), aluminum chloride (Synth), and palmitic acid (Vetec) were of analytical grade and used as received.

2.2. Preparation of Layered Double Hydroxides. Layered double hydroxides were produced by coprecipitation method, as previously reported [11].

Reaction for the production of $\mathrm{Zn} / \mathrm{Al}$ palmitate is as follows:

$$
\begin{gathered}
0.67 \mathrm{Zn}^{+2}+0.33 \mathrm{Al}^{+3}+\left(\mathrm{C}_{16} \mathrm{H}_{31} \mathrm{O}_{2}\right)^{-1} \text { excess }+2 \mathrm{OH}^{-1} \\
\longrightarrow \mathrm{Zn}_{0.67} \mathrm{Al}_{0.33}(\mathrm{OH})_{2}\left(\mathrm{C}_{16} \mathrm{H}_{31} \mathrm{O}_{2}\right)_{0.33} n \mathrm{H}_{2} \mathrm{O}
\end{gathered}
$$

$n$ is a variable number of water molecules.

2.3. Preparation of Layered Hydroxide Salts. Zinc hydroxide nitrate $(\mathrm{ZHN}), \mathrm{Zn}_{5}(\mathrm{OH})_{8}\left(\mathrm{NO}_{3}\right)_{2} 2 \mathrm{H}_{2} \mathrm{O}$, was prepared by adding aqueous ammonium hydroxide to a solution of zinc nitrate. The aqueous synthesis solution/suspension $\mathrm{pH}$ was maintained close to 7 and it was stirred vigorously for 24 hours at room temperature. The mixture was centrifuged at $4000 \mathrm{rpm}$ for 10 minutes, the supernatant was discarded, and the precipitate was washed with deionized water; these processes were repeated for five times. The solids were dried in an oven for one week at $60^{\circ} \mathrm{C}$.

Reaction for the production of $\mathrm{ZHN}$ is as follows:

$$
\begin{gathered}
5 \mathrm{Zn}^{+2}+2\left(\mathrm{NO}_{3}\right)^{-1}+8(\mathrm{OH})^{-1}+2 \mathrm{H}_{2} \mathrm{O} \\
\longrightarrow \mathrm{Zn}_{5}(\mathrm{OH})_{8}\left(\mathrm{NO}_{3}\right)_{2} 2 \mathrm{H}_{2} \mathrm{O}
\end{gathered}
$$

After that, in the anionic exchange reaction of the $\mathrm{ZHN}$, nitrate anions were exchanged by selected anions (salicylate or palmitate). In this process, ZHN was added to an intercalating agent solution and this mixture was vigorously stirred for three days, after which the exchanged layered hydroxide salt suspension was centrifuged at $4000 \mathrm{rpm}$ for 10 minutes and washed with deionized water. The centrifugation and washing processes were repeated for five times and the solids were dried in an oven at $60^{\circ} \mathrm{C}$ for seven days.

Exchange reactions are as follows:

Palmitate anion:

$$
\begin{aligned}
& \mathrm{Zn}_{5}(\mathrm{OH})_{8}\left(\mathrm{NO}_{3}\right)_{2} 2 \mathrm{H}_{2} \mathrm{O}+2\left(\mathrm{C}_{16} \mathrm{H}_{31} \mathrm{O}_{2}\right)^{-1} \\
& \longrightarrow \mathrm{Zn}_{5}(\mathrm{OH})_{8}\left(\mathrm{C}_{16} \mathrm{H}_{31} \mathrm{O}_{2}\right)_{2} 2 \mathrm{H}_{2} \mathrm{O}+2 \mathrm{NO}_{3}{ }^{-}
\end{aligned}
$$


Salicylate anion:

$$
\begin{aligned}
& \mathrm{Zn}_{5}(\mathrm{OH})_{8}\left(\mathrm{NO}_{3}\right)_{2} 2 \mathrm{H}_{2} \mathrm{O}+2\left(\mathrm{C}_{7} \mathrm{H}_{5} \mathrm{O}_{3}\right)^{-1} \\
& \longrightarrow \mathrm{Zn}_{5}(\mathrm{OH})_{8}\left(\mathrm{C}_{7} \mathrm{H}_{5} \mathrm{O}_{3}\right)_{2} 2 \mathrm{H}_{2} \mathrm{O}+2 \mathrm{NO}_{3}{ }^{-}
\end{aligned}
$$

2.4. Preparation of PLLA Nanocomposites. PLLA nanocomposites were produced by in situ intercalative ring opening polymerization of L-lactide, using stannous octoate, as catalyst. The L-lactide: catalyst molar ratio was fixed at $500: 1$. Prior to polymerization, the respective filler (1 or $2 \mathrm{wt} \%$ ) was mixed with L-lactide and catalyst and this mixture was vigorously stirred for 1 hour. Subsequently, the mixture was charged in a reactor and the polymerization was carried out at $120^{\circ} \mathrm{C}$ for 7 hours under dynamic flow of nitrogen.

2.5. Characterizations. The X-ray diffraction measurements (XRD) were performed using a Shimadzu-XRD 7000 diffractometer, using $\mathrm{CuK}_{\alpha}$ radiation $(\lambda=1.5406 \AA)$, at a rate of $2^{\circ} / \mathrm{min}$, operating at $40 \mathrm{KV}$ and $30 \mathrm{~mA}$, over $2 \theta$ range of $1.5-70^{\circ}$.

The FTIR spectra were obtained in a Spectrum One Perkin Elmer equipment, in a wavenumber range of 400 to $4000 \mathrm{~cm}^{-1}$, with a resolution of $4 \mathrm{~cm}^{-1}$. Measurements were recorded in the transmittance mode.

The UV-Vis transmittance spectra of the nanocomposites were obtained in a spectrophotometer Varian/Cary $5 \mathrm{G}$ equipment in the wavelength range of 200 to $800 \mathrm{~nm}$.

Thermogravimetric analysis (TGA) was performed on a Universal V2.3C TA Instrument, where the samples were heated from 30 to $700^{\circ} \mathrm{C}$, with a heating rate of $20^{\circ} \mathrm{C} / \mathrm{min}$ on oxidant atmosphere (oxygen flow of $100 \mathrm{ml} / \mathrm{min}$ ).

For XRD, FTIR, UV-Vis, and TGA analyses, the nanocomposite samples were ground (using an IKA All equipment) and then passed through a 100 -mesh sieve.

In order to carry out the mechanical tests, the samples were injection molded using a Haake Minijet injection molding system from Thermo Fisher Scientific. The injection molding conditions adopted were cylinder temperature of $200^{\circ} \mathrm{C}$, injection pressure of $200 \mathrm{bar}$, injection time of 10 seconds, mold temperature of $43^{\circ} \mathrm{C}$, holding pressure of 150 bar, and a holding time of 15 seconds. The specimens had $64 \mathrm{~mm}$ length, $12.7 \mathrm{~mm}$ width, and $3.2 \mathrm{~mm}$ thickness.

The flexural properties were measured using MTS testing machine model 810 , considering a three-point loading system. The testing speed was $5 \mathrm{~mm} / \mathrm{min}$ and span length was $30 \mathrm{~mm}$. Three specimens were tested for each sample of nanocomposite.

\section{Results and Discussions}

3.1. Layered Double Hydroxide and Layered Hydroxide Salts. Figure 1 exhibits the XRD patterns for salicylic acid, ZHN, and LHS (salicylate) while Figure 2 displays the X-ray diffraction patterns for palmitic acid, $\mathrm{Zn} / \mathrm{Al}$ palmitate, $\mathrm{ZHN}$, and LHS (palmitate). The basal spacing of the fillers was calculated by Bragg's equation, using the position of the higher order basal peaks.

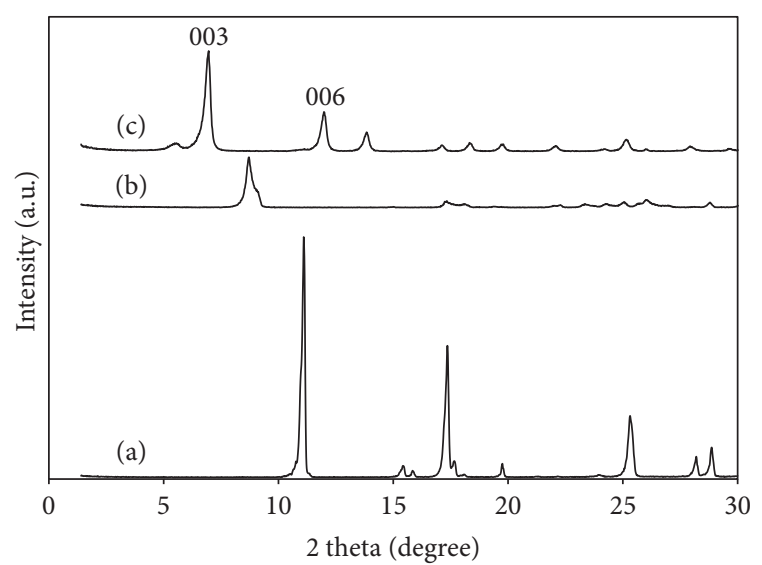

FIGURE 1: X-ray diffraction patterns: (a) salicylic acid, (b) zinc hydroxide nitrate $(\mathrm{ZHN})$, and (c) zinc hydroxide nitrate intercalated by the anion salicylate (LHS (salicylate)).

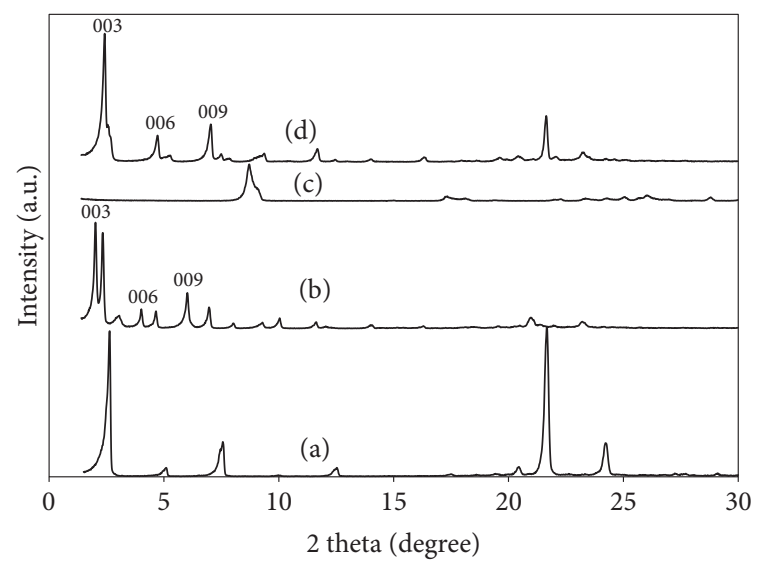

FIGURE 2: X-ray diffraction patterns: (a) palmitic acid, (b) Zn/Al palmitate, (c) zinc hydroxide nitrate (ZHN), and (d) zinc hydroxide nitrate intercalated by the anion palmitate (LHS (palmitate)).

Zinc hydroxide nitrate revealed a basal spacing of $9.79 \AA$, contaminated with a minor phase with basal distance of $10.23 \AA$, which is very close to $9.78 \AA$, value reported previously in literature [15]. XRD pattern of the LHS (salicylate) revealed two series of basal reflections, which correspond to basal spacing of $12.77 \AA$ (main phase) and $14.8 \AA$ (contamination). The presence of two crystalline phases may indicate two different packing modes of the organic anions in the interlayer spacing. It has been proposed [16] that there are several packing modes for the organic hydrocarbon chains in the interlayer, including monolayer, bilayer, or antiparallel packing at a slant angle with respect to the hydroxide layer. In general, the packing mode of organic anions in the gallery is mainly determined by their chain structure, that is, the chain length and the chain cross section, and is little affected by the charge density on the hydroxide layer [16].

Figure 2 shows that the LDH (palmitate) exhibited two different series of basal reflections, with basal spacing of $44.15 \AA$ and $38.16 \AA$. It is believed that, in the interlayer spacing of this $\mathrm{LDH}$, the anionic species can be arranged 


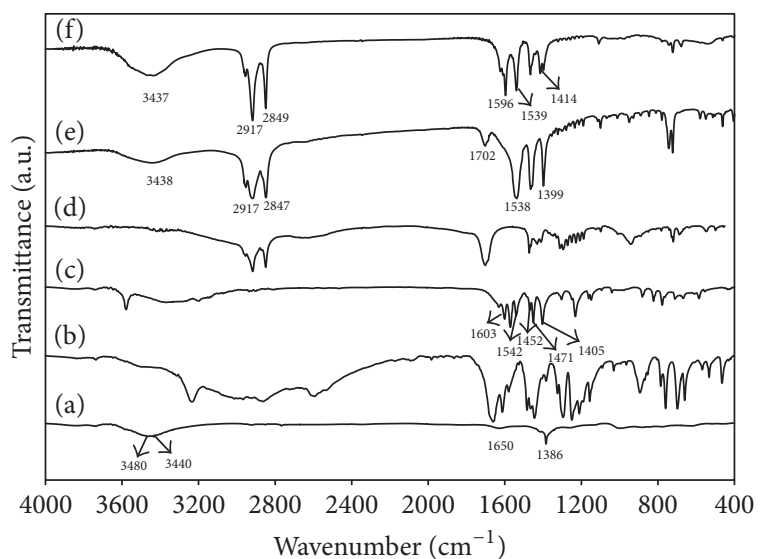

FIGURE 3: FTIR spectra of the fillers: (a) zinc hydroxide nitrate (ZHN), (b) salicylic acid, (c) LHS (salicylate), (d) palmitic acid, (e) LHS (palmitate), and (f) $\mathrm{Zn} / \mathrm{Al}$ palmitate.

in bilayer packing (basal spacing of $44.15 \AA$ ). In this case, hydrogen bonding of neutral $\mathrm{COOH}$ groups with adjacent $\mathrm{COO}^{-1}$ occurs. According to the literature [16], when the hydrocarbon chain contains 14-18 carbons and the supplied amount of the organic anion is more than the anion exchange capacity, a so-called bilayer packing mode is also observed. In this last case, neutral palmitic acid can also be cointercalated into the interlayer spacing, forming hydrogen bonds with carboxylate anions or hydroxide groups. The phase observed at $38.16 \AA$ is attributed to zinc palmitate.

LHS (palmitate) displayed a basal spacing of $36.98 \AA$. This filler exhibited several diffraction peaks, especially one close to $21^{\circ}$ ( 2 theta) that can be related to palmitic acid, as a contaminant, not completely eliminated during washing procedure.

Figure 3 shows the FTIR spectra of the fillers studied. The broad band at around $3500 \mathrm{~cm}^{-1}$ can be attributed to stretching vibration of the $\mathrm{O}-\mathrm{H}$ group. ZHN spectra revealed a band at $1386 \mathrm{~cm}^{-1}$ which is associated with the intercalated nitrate anions. None of the LHS intercalated by organic anions exhibited the band related to nitrate anions, which can indicate a total replacement of these anions by the organic anions studied. ZHN spectra showed bands at $3480 \mathrm{~cm}^{-1}$ and $3440 \mathrm{~cm}^{-1}$ (stretching vibrations of the O$\mathrm{H}$ groups) and $1650 \mathrm{~cm}^{-1}$ (angular deformation of the $\mathrm{O}$ $\mathrm{H}$ groups from water molecules). These bands can also be attributed to hydroxyl groups of the hydroxide layers and/or physisorbed and intercalated water molecules. The FTIR spectra of the layered compounds intercalated by the anion palmitate revealed bands close to $2920 \mathrm{~cm}^{-1}$ and $2850 \mathrm{~cm}^{-1}$, which can represent symmetric and asymmetric stretching vibrations of the $\mathrm{C}-\mathrm{H}$ groups, respectively.

LDH (palmitate) and LHS (salicylate) samples showed a band close to $1600 \mathrm{~cm}^{-1}$, which can be associated with carbonyl stretching vibrations of acid as contaminant or due to $\mathrm{H}$-bonding of free acid with carboxylate and/or pendant layer hydroxide groups [17]. These results are in agreement with those obtained by XRD and both of them indicated the formation of two phases. LDH (palmitate), LHS (palmitate),

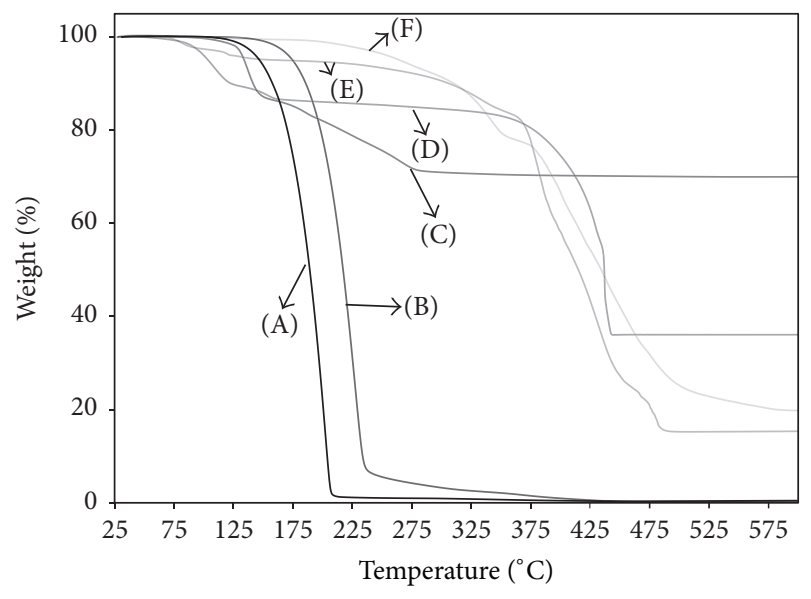
(A) Salicylic acid
(D) LHS (salicylate)
(B) Palmitic acid
(E) LHS (palmitate)
(C) ZHN
(F) $\mathrm{Zn} / \mathrm{Al}$ palmitate

FIGURE 4: TGA curves of intercalating anion precursors and fillers produced.

and LHS (salicylate) exhibited bands close to $1540 \mathrm{~cm}^{-1}$ and $1400 \mathrm{~cm}^{-1}$, which can correspond to asymmetric and symmetric stretching vibration of the $\mathrm{C}=\mathrm{O}$ group, respectively.

The spectra of LHS (palmitate) exhibited a band at $1702 \mathrm{~cm}^{-1}$. This band also is observed in the palmitic acid spectra and it corresponds to the stretching vibration of the $\mathrm{C}=\mathrm{O}$ group of the protonated carboxylate. This fact can indicate that palmitic acid is present as a contaminant.

LHS (salicylate) spectra exhibited bands at $1471 \mathrm{~cm}^{-1}$ and $1452 \mathrm{~cm}^{-1}$ which can be related to $\mathrm{C}=\mathrm{C}$ stretching vibration of the aromatic rings.

Figure 4 shows thermogravimetric curves (TGA) for the oxidative thermal decomposition of the intercalating anion precursors and the layered compounds produced. Salicylic acid and palmitic acid showed decomposition temperatures close to $350^{\circ} \mathrm{C}$ (char residue of $0.7 \%$ ) and $430^{\circ} \mathrm{C}$ (char residue of $0.5 \%$ ), respectively.

$\mathrm{Zn} / \mathrm{Al}$ palmitate showed thermal decomposition until $570^{\circ} \mathrm{C}$ with a char residue of $20 \%$. ZHN, LHS (salicylate), and LHS (palmitate) exhibited thermal decomposition until $280^{\circ} \mathrm{C}$ (char residue of $71 \%$ ), $443^{\circ} \mathrm{C}$ (char residue of $36 \%$ ), and $488^{\circ} \mathrm{C}$ (char residue of $15 \%$ ), respectively. These results showed that anionic exchange reaction promoted an enhancement in the thermal stability of the layered hydroxide salt.

3.2. Polymer Nanocomposites. Figure 5 displays the $\mathrm{X}$-ray diffraction patterns for PLLA and PLLA nanocomposites. Comparing the XRD patterns of the nanocomposites to the PLLA, it can be noticed that they are very similar, since the diffraction peaks related to the layered materials are absent. This fact can indicate that the inorganic fillers are exfoliated in the polymeric matrix. However, as the studied concentrations of the LDH or LHS were very low ( $1 \mathrm{wt} \%$ or $2 \mathrm{wt} \%$ ), the diffraction peaks related to these layered compounds may not have been detected by the equipment. In order to verify 


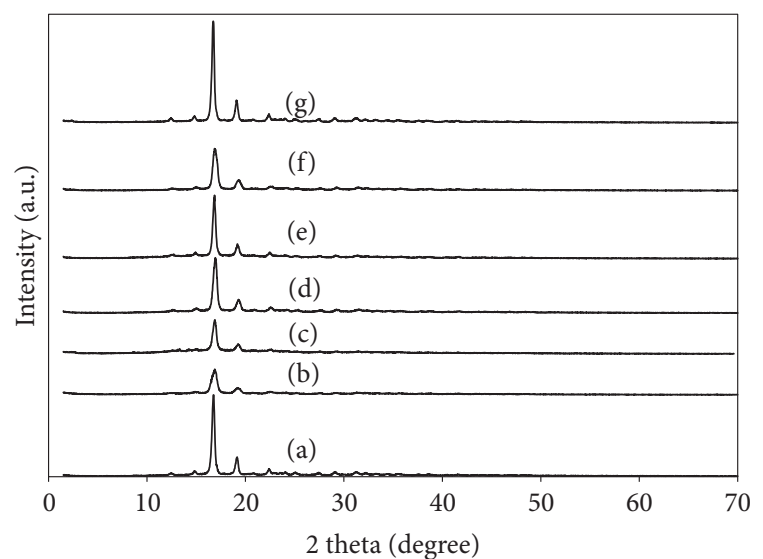

Figure 5: X-ray diffraction patterns of PLLA (a) and PLLA nanocomposites (b-g), (b) $\mathrm{Zn} / \mathrm{Al}$ palmitate (1 wt\%), (c) $\mathrm{Zn} / \mathrm{Al}$ palmitate (2 wt\%), (d) LHS (salicylate) (1 wt\%), (e) LHS (salicylate) (2 wt\%), (f) LHS (palmitate) (1 wt\%), and (g) LHS (palmitate) (2wt\%).

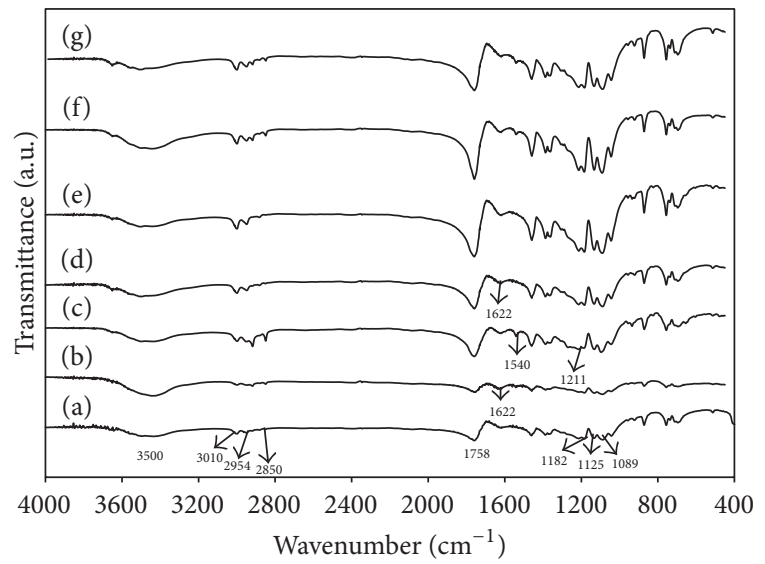

FIgURE 6: FTIR spectra of PLLA (a) and PLLA nanocomposites (b-g), (b) $\mathrm{Zn} / \mathrm{Al}$ palmitate (1 wt\%), (c) $\mathrm{Zn} / \mathrm{Al}$ palmitate (2 $\mathrm{wt} \%$ ), (d) LHS (salicylate) (1wt\%), (e) LHS (salicylate) (2 wt\%), (f) LHS (palmitate) (1 wt\%), and (g) LHS (palmitate) (2 wt\%).

the dispersion of the filler, it would be important to perform TEM images. TEM allows a qualitative understanding of the internal structure, spatial distribution of the various phases, and views of the defect structure through direct visualization [1]. Unfortunately, it was not possible to carry out TEM images because some nanocomposites started to undergo degradation two weeks after they had been produced.

Figure 6 exhibits the FTIR spectra of PLLA and PLLA nanocomposites. All the nanocomposites revealed FTIR spectra very similar to the ones obtained for PLLA. The band centered around $3500 \mathrm{~cm}^{-1}$ can be attributed to O-H stretching vibrations. Bands close to $3000 \mathrm{~cm}^{-1}, 2950 \mathrm{~cm}^{-1}$, and $2850 \mathrm{~cm}^{-1}$ can be related to $\mathrm{C}-\mathrm{H}$ stretching vibrations. The band at $1760 \mathrm{~cm}^{-1}$ can be assigned to carbonyl stretching vibration. Bands close to $1180 \mathrm{~cm}^{-1}, 1130 \mathrm{~cm}^{-1}$, and $1090 \mathrm{~cm}^{-1}$ can be attributed to $\mathrm{C}-\mathrm{O}$ stretching vibrations.

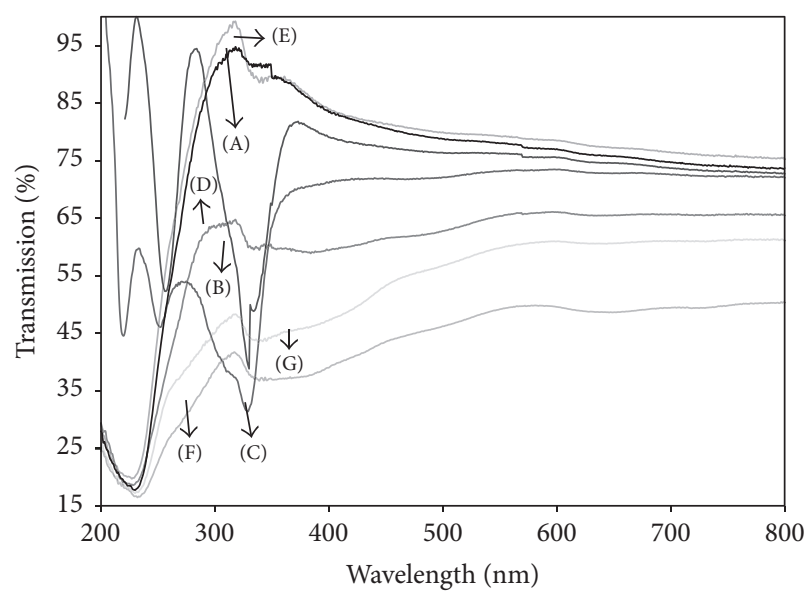
(A) PLLA
(E) $2 \mathrm{wt} \%$ of LHS (palmitate)
(B) $1 \mathrm{wt} \%$ of LHS (salicylate)
(C) $2 \mathrm{wt} \%$ of LHS (salicylate)
(F) $1 \mathrm{wt} \%$ of $\mathrm{Zn} / \mathrm{Al}$ palmitate
(G) $2 \mathrm{wt} \%$ of $\mathrm{Zn} / \mathrm{Al}$ palmitate

(D) $1 \mathrm{wt} \%$ of LHS (palmitate)

Figure 7: Percent transmission versus wavelength of PLLA (A) and PLLA nanocomposites (B-G).

The spectrum of the nanocomposite containing $2 \mathrm{wt} \%$ of $\mathrm{Zn} / \mathrm{Al}$ palmitate revealed extra bands at $1540 \mathrm{~cm}^{-1}$ (this band also appeared in the $\mathrm{Zn} / \mathrm{Al}$ palmitate $\mathrm{LDH}$ spectra) and at $1211 \mathrm{~cm}^{-1}$, which can be associated with carboxylate asymmetric stretching vibrations and $\mathrm{C}-\mathrm{O}$ asymmetric stretching vibrations, respectively. The spectra of the nanocomposites containing $1 \mathrm{wt} \%$ of $\mathrm{Zn} / \mathrm{Al}$ palmitate and $1 \mathrm{wt} \%$ of LHS (salicylate) revealed a band at $1622 \mathrm{~cm}^{-1}$, which can be related to $\mathrm{C}=\mathrm{O}$ asymmetric stretching vibrations of an undissociated carboxylic acid group (COOH). The appearance of this band can be attributed to cointercalation of neutral carboxylic acid in the layered compounds interlayer spacing and/or can indicate that the excess of the acid was not completely removed during the washing procedure.

Visible and ultraviolet transmission spectra of PLLA and PLLA nanocomposites can be seen in Figure 7.

The ultraviolet light includes the wavelength range $100-400 \mathrm{~nm}$ that is divided into three distinct regions of wavelengths, UVA (400-315 nm), UVB (315-280 nm), and UVC (280-100 nm). The visible light covers the wavelength ranging from 400 to $700 \mathrm{~nm}$.

The transmission of visible and ultraviolet light is important parameter in designing the right packaging to preserve and protect products until they reach the consumer [18]. At UVC region, PLLA exhibited light transmittance that ranged from $18 \%(233 \mathrm{~nm})$ to $76 \%(280 \mathrm{~nm})$. At UVB region, it can be observed that the PLLA transmittance increased significantly, reaching a light transmission of $93 \%$ at $315 \mathrm{~nm}$. The highest amount of UV light transmitted by PLLA occurred in UVA region, at $318 \mathrm{~nm}(95 \%)$. At visible region, PLLA showed the highest transmittance at $400 \mathrm{~nm}(83 \%)$. The transparency of plastic sheeting is defined as the transmission of visible light on the range $540-560 \mathrm{~nm}$ [18]. In this range, the average PLLA transmittance was $78 \%$. 
TABLE 1: Temperatures for the thermal degradation of PLLA and PLLA nanocomposites.

\begin{tabular}{lccc}
\hline Sample & $T_{10}\left({ }^{\circ} \mathrm{C}\right)$ & $T_{50}\left({ }^{\circ} \mathrm{C}\right)$ & $T_{d}\left({ }^{\circ} \mathrm{C}\right)$ \\
\hline PLLA & 246 & 277 & 301 \\
PLLA/(1 wt\% of Zn/Al palmitate) & 281 & 308 & 352 \\
PLLA/(2 wt\% of Zn/Al palmitate) & 251 & 286 & 323 \\
PLLA/(1 wt\% of LHS (salicylate)) & 249 & 281 & 308 \\
PLLA/(2 wt $\%$ of LHS (salicylate) $)$ & 233 & 269 & 301 \\
PLLA/(1 wt $\%$ of LHS (palmitate) $)$ & 249 & 280 & 318 \\
PLLA/(2 wt $\%$ of LHS (palmitate) $)$ & 242 & 272 & 301 \\
\hline
\end{tabular}

With exception of the samples with LHS (salicylate), PLLA and other nanocomposites exhibited very similar percent transmission versus wavelength curves, with bands close to $320 \mathrm{~nm}$. The samples containing LHS (salicylate) displayed bands close to $230 \mathrm{~nm}$ and $280 \mathrm{~nm}$. These bands could be a characteristic of the samples containing LHS (salicylate).

Both the nanocomposites containing LDHs (palmitate) exhibited lower transmittance than PLLA, in the entire wavelength range analyzed.

Compared to PLLA, the nanocomposite containing $2 \mathrm{wt} \%$ of LHS (salicylate) transmitted a smaller amount of UVA and UVB light. This nanocomposite revealed transmittance that ranged from 37 to $54 \%$, in the UVB region. In the UVA region, this nanocomposite transmitted within the range 32 to $73 \%$ and it exhibited a transparency over $73 \%$. The nanocomposite containing $1 \mathrm{wt} \%$ of LHS (palmitate) transmitted less light than PLLA, in the entire wavelength studied, and exhibited a transparency over $65 \%$. The nanocomposite with 2 wt $\%$ of LHS (palmitate) displayed transmittance values very similar to PLLA. According to some authors [18], UV-C and UV-B wavelengths are the most damaging for food. The most promising results were found for the nanocomposite containing $2 \mathrm{wt} \%$ of LHS (salicylate) because, compared to PLLA, it transmitted less light from $250 \mathrm{~nm}$, while keeping a similar transparence.

Figure 8 shows thermogravimetric curves for the oxidative thermal decomposition processes of PLLA and PLLA nanocomposites. Figure 9 exhibits the derivatives of these curves (DTGA). Table 1 displays a summary of thermogravimetric data. This table displays the data of the onset degradation temperature $T_{10}$ (temperature at which $10 \%$ of the mass is lost), the midpoint degradation temperature $T_{50}$ (temperature at which $50 \%$ of the mass is lost), and the total degradation temperature $T_{d}$. The residue left after combustion of unfilled polymer in air is nearly zero as all the organic contents (hydrocarbon) are converted into gaseous products. In the case of the nanocomposites, the polymeric matrix and the organic part in LDHs are completely burnt and are lost as gaseous products [19].

It can be noticed that, with exception of the nanocomposites containing $2 \mathrm{wt} \%$ of LHS (salicylate) and $2 \mathrm{wt} \%$ of LHS (palmitate), all other nanocomposites were more thermally stable than PLLA, at all the conditions studied. The nanocomposite with $1 \mathrm{wt} \%$ of $\mathrm{Zn} / \mathrm{Al}$ palmitate exhibited the highest thermal stability. Compared to PLLA, this

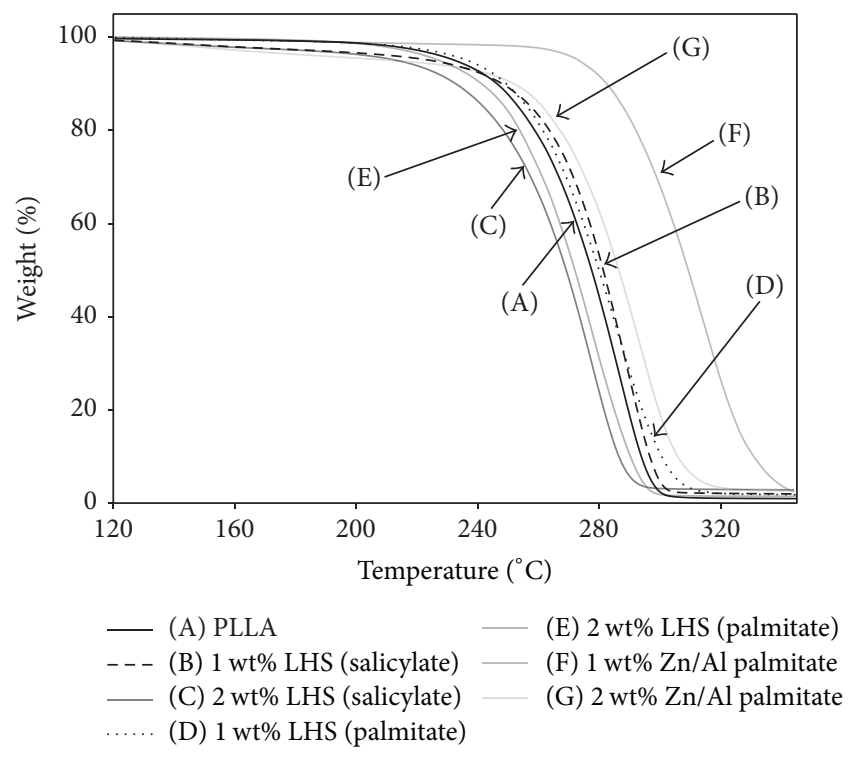

Figure 8: TGA curves to PLLA (A) and PLLA nanocomposites (B-G).

nanocomposite displayed $T_{10}, T_{50}$, and $T_{d}$ about 36, 31, and $51^{\circ} \mathrm{C}$ higher than the ones obtained for pure PLLA. The enhancement on the thermal stability can be attributed to the filler homogeneously dispersed in the PLLA matrix. During the thermal decomposition, these fillers generate char or inorganic residues that can act as mass transport barrier, reducing the transport of volatile gases out of the nanocomposites. Besides, for large filler/PLLA interfaces, the strong chemical and physical interactions between the layered compounds and the PLLA restrict the thermal motion of the polymer molecules, increasing thermal stability. It can be seen that an increase on the filler concentration caused a decrease on thermal stability. This fact can be related to the dispersion of the filler that can be negatively affected as the concentration increased, limiting, this way, the insulating effect of the char and reducing the polymer/filler interfacial interactions.

DTGA curves of all the samples (PLLA and nanocomposites) showed only one thermal event, attributed to decomposition of PLLA chains.

Figure 10 displays stress versus strain curves for PLLA and PLLA nanocomposites. Table 2 exhibits a summary of 
TABLE 2: Summary of some parameters obtained from flexure test.

\begin{tabular}{lcccc}
\hline & $\begin{array}{c}\text { Modulus of elasticity } \\
(\mathrm{MPa})\end{array}$ & $\begin{array}{c}\text { Stress at yield point } \\
(\mathrm{MPa})\end{array}$ & $\begin{array}{c}\text { Stress at break point } \\
(\mathrm{MPa})\end{array}$ & $\begin{array}{c}\text { Elongation at break } \\
(\%)\end{array}$ \\
\hline PLLA & 3815 & - & 20.6 & 0.54 \\
PLLA/(1 wt\% Zn/Al palmitate) & 3378 & 29.2 & 25.7 & 0.92 \\
PLLA/(2 wt\% Zn/Al palmitate) & 2521 & 23.7 & 6.3 & 1.4 \\
PLLA/(1 wt\% LHS (salicylate)) & 3296 & - & 20.6 & 0.3 \\
PLLA/(2 wt\% LHS (salicylate)) & 2585 & 14.9 & 2.95 & 0.3 \\
PLLA/(1 wt\% LHS (palmitate)) & 2619 & - & 12.5 & 0.5 \\
PLLA/(2 wt\% LHS (palmitate)) & 3259 & - & 0.38 \\
\hline
\end{tabular}

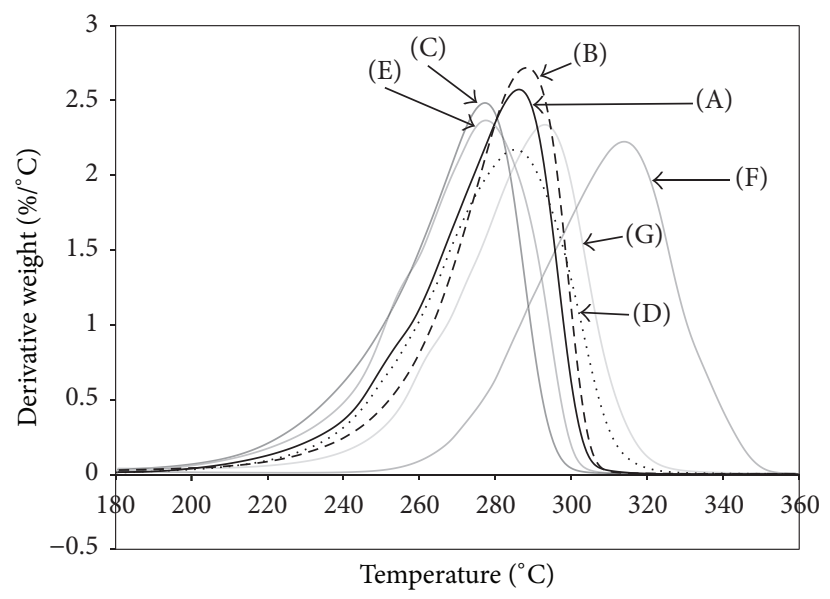
(A) PLLA
(E) $2 \mathrm{wt} \%$ LHS (palmitate)
- - - (B) 1 wt\% LHS (salicylate)
- (C) $2 \mathrm{wt} \%$ LHS (salicylate)
(D) $1 \mathrm{wt} \%$ LHS (palmitate)
(F) $1 \mathrm{wt} \% \mathrm{Zn} / \mathrm{Al}$ palmitate
(G) $2 \mathrm{wt} \% \mathrm{Zn} / \mathrm{Al}$ palmitate

Figure 9: DTGA curves to PLLA (A) and PLLA nanocomposites $(\mathrm{B}-\mathrm{G})$.

the main parameters (modulus of elasticity, stress at yield point, stress at break point, and elongation at break point) obtained from flexural test. Compared to PLLA, all the nanocomposites exhibited lower elasticity modulus values.

Results showed that as the filler concentration increased from $1 \mathrm{wt} \%$ to $2 \mathrm{wt} \%$ there was a reduction in the maximum flexural stress values. The increase in filler concentration may have resulted in a less efficient dispersion of the layered compounds, which could lead to weaker physical and/or chemical interactions between them and the PLLA matrix. This may have caused the formation of small tactoids that act as sites of stress concentration.

The curve of PLLA and most of the nanocomposites exhibited only break point. These samples fractured when a maximum flexural stress was reached. On the other hand, the curve of the nanocomposite containing $2 \mathrm{wt} \%$ of $\mathrm{Zn} / \mathrm{Al}$ palmitate exhibited a different behavior because it displayed yield point and break point. This sample exhibited an increase in strain after the maximum flexural stress was reached. The highest maximum flexural stress was found for the sample

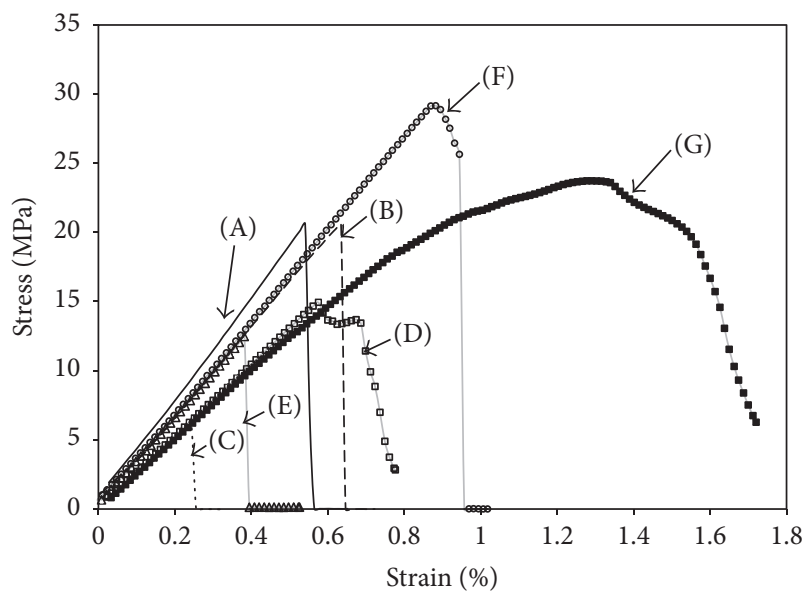
(A) PLLA
(E) $2 \mathrm{wt} \%$ LHS (palmitate)
(B) $1 \mathrm{wt} \%$ LHS (salicylate)
(C) $2 \mathrm{wt} \%$ LHS (salicylate)
(D) $1 \mathrm{wt} \%$ LHS (palmitate)
(F) $1 \mathrm{wt} \% \mathrm{Zn} / \mathrm{Al}$ palmitate
(G) $2 \mathrm{wt} \% \mathrm{Zn} / \mathrm{Al}$ palmitate

FIGURE 10: Stress versus strain curves derived from flexure tests to PLLA (A) and PLLA nanocomposites (B-G).

containing $1 \mathrm{wt} \%$ of $\mathrm{Zn} / \mathrm{Al}$ palmitate, whose value was almost $42 \%$ higher than the one found for PLLA.

The sample containing $2 \mathrm{wt} \%$ of $\mathrm{Zn} / \mathrm{Al}$ palmitate displayed the highest strain at break value and also exhibited a maximum flexural stress value $15 \%$ higher than the one found for PLLA. Compared to PLLA, this sample exhibited an increase of almost $160 \%$ in the strain at break value, showing a less fragile behavior. This result displayed that it was possible to cause an alteration in the PLLA plastic deformation through the addition of a low concentration of a selected layered filler. In this case, it was possible to promote a higher flexibility without reducing the flexural stress, revealing an advantage of the $\mathrm{Zn} / \mathrm{Al}$ palmitate under the plasticizers that have been used so far for PLLA.

\section{Conclusions}

In the present study, the effect of three different fillers (Zn/Al palmitate, LHS (salicylate), and LHS (palmitate)) on the mechanical and thermal properties of poly(L-lactide) nanocomposites was evaluated. 
The nanocomposite containing $1 \mathrm{wt} \%$ of $\mathrm{Zn} / \mathrm{Al}$ palmitate exhibited a decomposition temperature $51^{\circ} \mathrm{C}$ higher than the one found for PLLA.

The results of flexure test evidenced that, compared to PLLA, the nanocomposite containing $1 \mathrm{wt} \%$ of $\mathrm{Zn} / \mathrm{Al}$ palmitate displayed a maximum flexural stress value $42 \%$ higher. The results showed that the strain at break value was remarkably increased in the case of the sample with $2 \mathrm{wt} \%$ of $\mathrm{Zn} / \mathrm{Al}$ palmitate.

\section{Conflicts of Interest}

The authors declare that they have no conflicts of interest.

\section{Acknowledgments}

The authors would like to acknowledge the financial support from FAPESP (Fundação de Amparo à Pesquisa do Estado de São Paulo), CNPq, FINEP, and PNPD/CAPES (Programa Nacional de Pós Doutorado).

\section{References}

[1] S. Sinha Ray and M. Okamoto, "Biodegradable polylactide and its nanocomposites: Opening a new dimension for plastics and composites," Macromolecular Rapid Communications, vol. 24, no. 14, pp. 815-840, 2003.

[2] M.-F. Chiang and T.-M. Wu, "Synthesis and characterization of biodegradable poly(l-lactide)/layered double hydroxide nanocomposites," Composites Science and Technology, vol. 70, no. 1, pp. 110-115, 2010.

[3] A. Arora and G. W. Padua, "Review: nanocomposites in food packaging," Journal of Food Science, vol. 75, no. 1, pp. R43-R49, 2010.

[4] K. L. Dagnon, R. Sri Ambadapadi, A. Shaito et al., "Poly(Llactic acid) nanocomposites with layered double hydroxides functionalized with ibuprofen," Journal of Applied Polymer Science, vol. 113, no. 3, pp. 1905-1915, 2009.

[5] V. Katiyar, N. Gerds, C. B. Koch, J. Risbo, H. C. B. Hansen, and D. Plackett, "Poly l-lactide-layered double hydroxide nanocomposites via in situ polymerization of l-lactide," Polymer Degradation and Stability, vol. 95, no. 12, pp. 2563-2573, 2010.

[6] V. Katiyar, N. Gerds, C. B. Koch, J. Risbo, H. C. B. Hansen, and D. Plackett, "Melt processing of poly(L-lactic acid) in the presence of organomodified anionic or cationic clays," Journal of Applied Polymer Science, vol. 122, no. 1, pp. 112-125, 2011.

[7] E. Mahboobeh, W. M. Z. W. Yunus, Z. Hussein, M. Ahmad, and N. A. Ibrahim, "Flexibility improvement of poly(lactic acid) by stearate-modified layered double hydroxide," Journal of Applied Polymer Science, vol. 118, no. 2, pp. 1077-1083, 2010.

[8] J. U. Ha and M. Xanthos, "Novel modifiers for layered double hydroxides and their effects on the properties of polylactic acid composites," Applied Clay Science, vol. 47, no. 3-4, pp. 303-310, 2010.

[9] M.-F. Chiang and T.-M. Wu, "Preparation and characterization of melt processed poly(l-lactide)/layered double hydroxide nonocomposites," Composites Part B: Engineering, vol. 43, no. 7, pp. 2789-2794, 2012.

[10] M.-F. Chiang, M.-Z. Chu, and T.-M. Wu, "Effect of layered double hydroxides on the thermal degradation behavior of biodegradable poly(l-lactide) nanocomposites," Polymer Degradation and Stability, vol. 96, no. 1, pp. 60-66, 2011.

[11] T. Nogueira, R. Botan, F. Wypych, and L. Lona, "Study of thermal and mechanical properties of PMMA/LDHs nanocomposites obtained by in situ bulk polymerization," Composites Part A: Applied Science and Manufacturing, vol. 42, no. 8, pp. 1025-1030, 2011.

[12] G. G. C. Arizaga, K. G. Satyanarayana, and F. Wypych, "Layered hydroxide salts: Synthesis, properties and potential applications," Solid State Ionics, vol. 178, no. 15-18, pp. 1143-1162, 2007.

[13] V. Katiyar and H. Nanavati, "In situ synthesis of high molecular weight poly(l-lactic acid) clay nanocomposites," Polymer Engineering and Science, vol. 51, pp. 2066-2077, 2011.

[14] T. Nogueira, R. Botan, J. C. MacEdo Neto, F. Wypych, and L. Lona, "Effect of layered double hydroxides on the mechanical, thermal, and fire properties of poly(methyl methacrylate) nanocomposites," Advances in Polymer Technology, vol. 32, no. 1, pp. E660-E674, 2013.

[15] R. Marangoni, L. P. Ramos, and F. Wypych, "New multifunctional materials obtained by the intercalation of anionic dyes into layered zinc hydroxide nitrate followed by dispersion into poly(vinyl alcohol) (PVA)," Journal of Colloid and Interface Science, vol. 330, no. 2, pp. 303-309, 2009.

[16] Z. P. Xu and P. S. Braterman, "Synthesis, structure and morphology of organic layered double hydroxide (LDH) hybrids: comparison between aliphatic anions and their oxygenated analogs," Applied Clay Science, vol. 48, no. 1-2, pp. 235-242, 2010.

[17] Z. P. Xu, P. S. Braterman, K. Yu, H. Xu, Y. Wang, and C. J. Brinker, "Unusual hydrocarbon chain packing mode and modification of crystallite growth habit in the self-assembled nanocomposites zinc-aluminum-hydroxide oleate and elaidate (cis- and trans- $[\mathrm{Zn} 2 \mathrm{Al}(\mathrm{OH}) 6(\mathrm{CH} \quad 3(\mathrm{CH} 2) 7 \mathrm{CH}=\mathrm{CH}(\mathrm{CH} 2)$ 7COO-)] and magnesium analogues," Chemistry of Materials, vol. 16, no. 14, pp. 2750-2756, 2004.

[18] R. Auras, B. Harte, and S. Selke, "An overview of polylactides as packaging materials," Macromolecular Bioscience, vol. 4, no. 9, pp. 835-864, 2004.

[19] F. R. Costa, U. Wagenknecht, and G. Heinrich, "LDPE/MgAl layered double hydroxide nanocomposite: Thermal and flammability properties," Polymer Degradation and Stability, vol. 92, no. 10, pp. 1813-1823, 2007. 

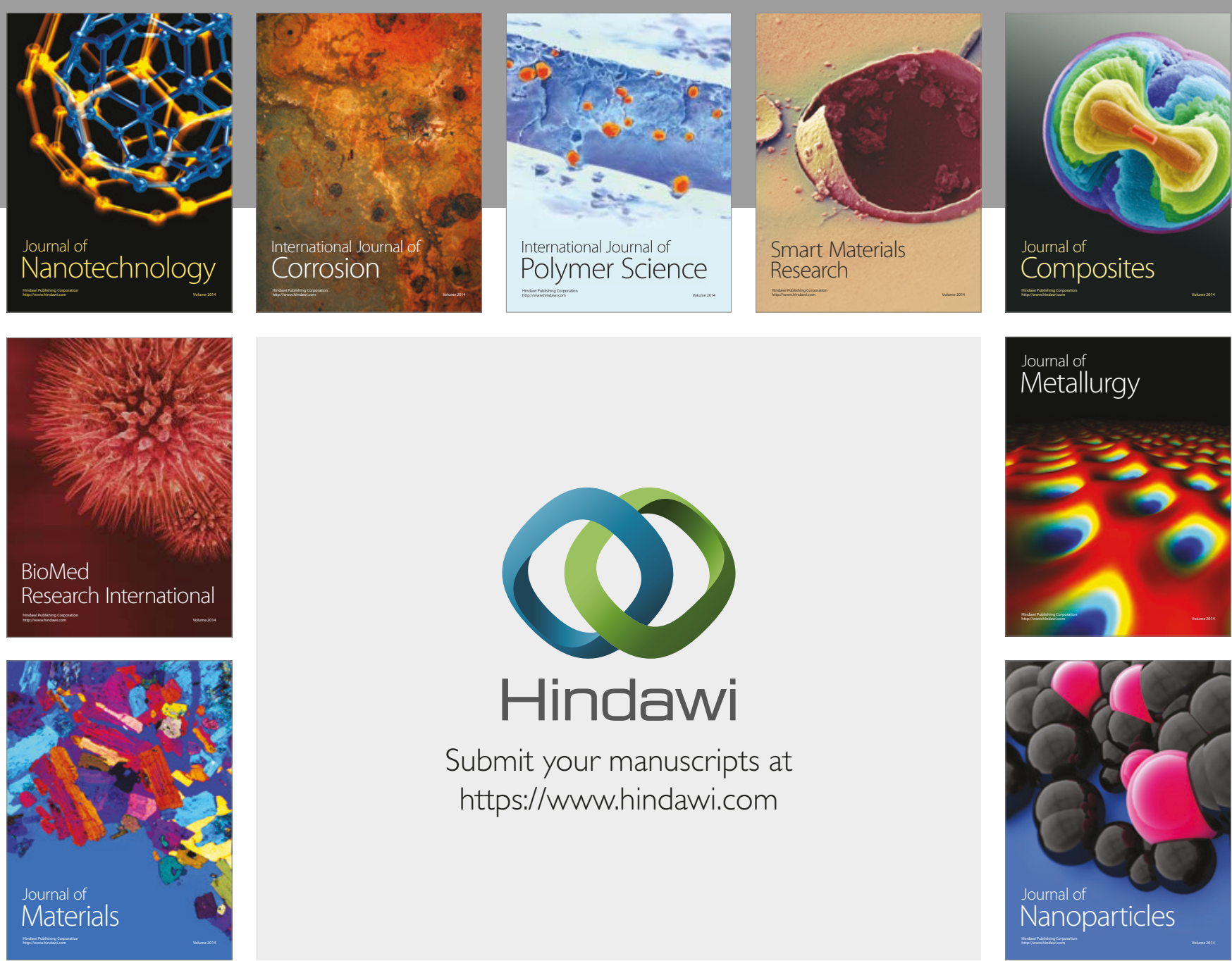

\section{Hindawi}

Submit your manuscripts at

https://www.hindawi.com
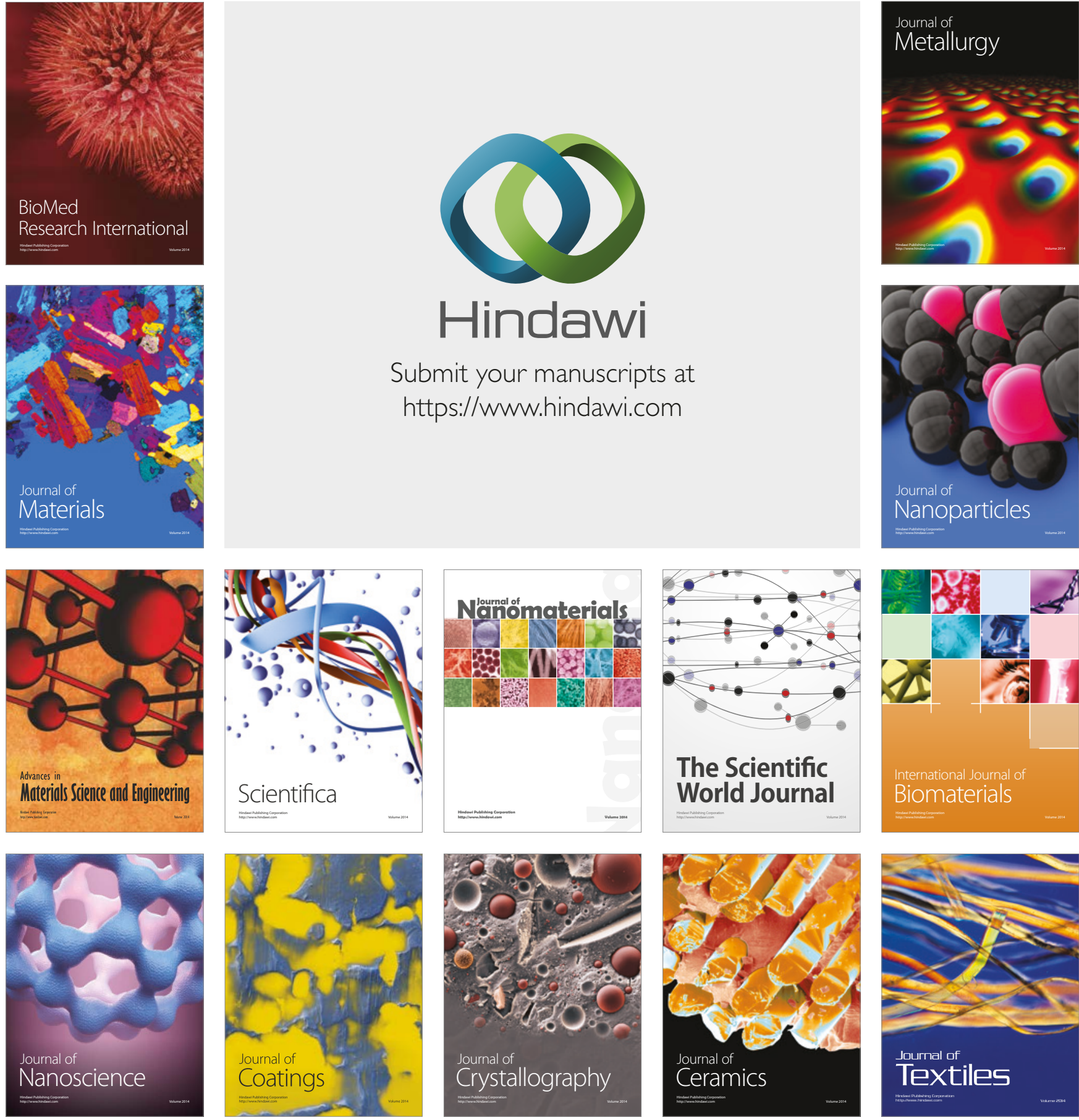

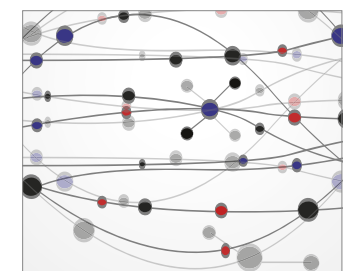

The Scientific World Journal
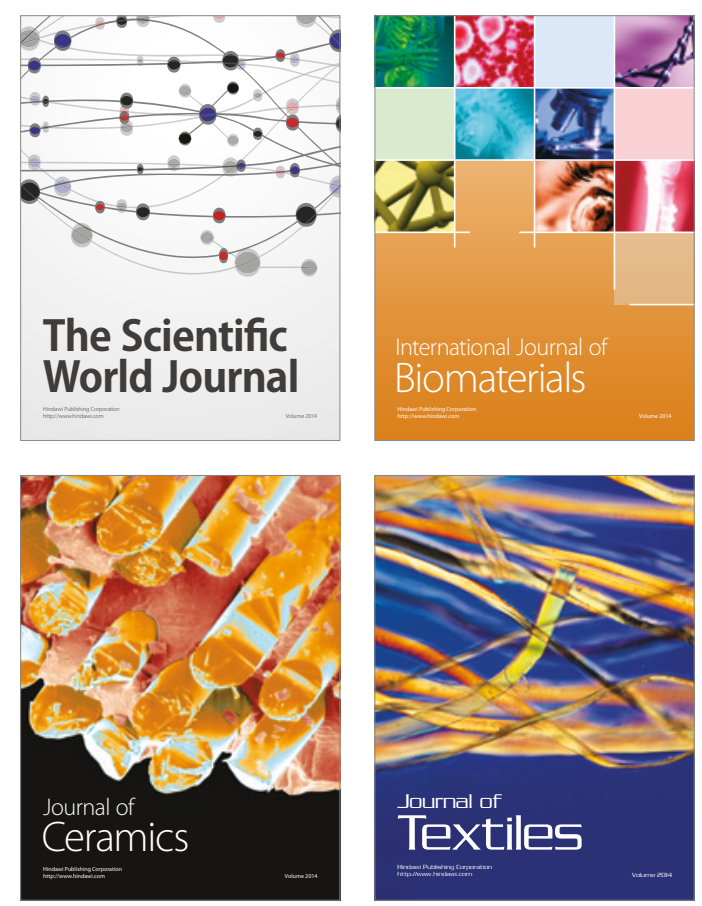